\title{
Detection of changes occurring during recovery from the dauer stage in Heterorhabditis bacteriophora
}

\author{
K. M. DOLAN ${ }^{1}$, J. T. JONES ${ }^{2}$ and A. M. BURNELL ${ }^{1 *}$ \\ ${ }^{1}$ Institute of Bioengineering and Agroecology and Department of Biology, National University of Ireland Maynooth, \\ Maynooth, Co Kildare, Ireland \\ ${ }^{2} M B N$ Unit, Scottish Crop Research Institute, Invergowrie, Dundee DD2 5DA, UK
}

(Received 16 November 2001 ; revised 13 February 2002; accepted 13 February 2002)

SUMMARY

Nematodes of the genus Heterorhabditis are insect parasites that are widely used as biological control agents. When conditions are unfavourable for reproduction in $H$. bacteriophora, a long-lived, non-feeding, survival and dispersal stage, the dauer juvenile (DJ), is formed. This DJ stage is also adapted for host finding and infection. When it infects a suitable host, the DJ recovers and resumes growth and development. We describe a series of methods for improved detection of recovery in $H$. bacteriophora. We also describe some of the physiological changes that occur immediately after the onset of recovery in these nematodes as revealed using fluorescent nucleic acid binding SYTO dyes. Although recovery could be monitored using morphological changes, we found that observation of the uptake of fluorescent latex microspheres by recovering nematodes was a far more sensitive and efficient means of detecting recovery. SYTO dyes were also found to be useful indicators of recovery, binding to the pharyngeal glands and genital primordia as little as $3 \mathrm{~h}$ after the onset of recovery. The use of SYTO dyes also indicated that the pharyngeal glands produce large quantities of RNA following the onset of recovery, implying that these structures may produce proteins important in the infection and/or feeding process of $H$. bacteriophora.

Key words: dauer recovery, gland cells, Heterorhabditis, SYTO dyes.

\section{INTRODUCTION}

Entomopathogenic nematodes of the genus Heterorhabditis are soil-dwelling parasites capable of infecting the majority of insect orders and families (Klein, 1990). Heterorhabditids have a complex lifecycle containing hermaphrodite and amphmictic generations which occur within the parasitized insect host (reviewed by Burnell \& Stock, 2000). These nematodes also harbour in their intestines symbiotic bacteria of the Enterobacteriaceae genus Photorhabdus (Boemare, Akhurst \& Mourant, 1993).

The non-feeding infective stage of Heterorhabditis is a modified 3rd-stage juvenile which is morphologically and physiologically adapted for dispersal, long-term survival in the soil, host finding and infection. This stage is known as the dauer juvenile (DJ). Heterorhabditid DJs respond chemotactically to insect hosts in the soil. They enter insect larvae through natural openings (mouth, anus, spiracles) or by penetrating the intersegmental membranes. Once in the insect haemocoel the DJ releases cells of its bacterial symbiont, which replicate rapidly and secrete insecticidal toxins and lytic enzymes. These

* Corresponding author: Institute of Bioengineering and Agroecology and Department of Biology, National University of Ireland Maynooth, Maynooth, Co Kildare, Ireland. Tel: +353 17083840 . Fax: +353 17083845 .

E-mail: ann.burnell@may.ie secretions are lethal to the insect, which normally dies within $48 \mathrm{~h}$ (Forst et al. 1997). The bacterial cells and digested host tissues provide a rich medium for the growth and reproduction of Heterorhabditis. The DJ resumes development and feeding and matures to become an adult hermaphrodite female. Nematode reproduction is prolific and continues over 2-3 generations at which point adult development is suppressed, DJs accumulate and begin to emerge into the soil. Within approximately 2 weeks of infection up to half a million DJs/gram of insect are produced (Akhurst \& Bedding, 1986).

Heterorhabditids are produced commercially for the biological control of a range of insect pests in agriculture and horticulture. Because they can complete their life-cycle in vitro (in contrast to the vast majority of animal- or plant-parasitic nematodes), heterorhabditids have the potential to be important model organisms for parasitic research. Heterorhabditis belongs to the same zoological family as Caenorhabditis elegans, an important technology development platform for nematode research (Grant \& Viney, 2001), and was the most closely related parasitic nematode to $C$. elegans in the phylogeny of Blaxter et al. (1998). When bacterial food is abundant, $C$. elegans develops rapidly through 4 juvenile stages to adulthood. When environmental conditions are unfavourable for reproduction (due to high population density and/or lack of food), $C$. 
elegans development is arrested and a long-lived, non-feeding, survival and dispersal stage is formed (Cassada \& Russell, 1975). This non-obligate 3rdstage DJ is homologus to the obligate DJ stage of Heterorhabditis. Food signals, environmental temperature and levels of the nematode pheromone (which is used to assess the degree of crowding) are important environmental cues to control exit from the dauer stage in C. elegans (Golden \& Riddle, 1984). Detection of the pheromone and bacterial food signals is mediated through specific amphidial neurons. The molecular pathways controlling the decision to enter and exit the dauer stage have been thoroughly investigated in C. elegans (Riddle \& Albert, 1997; Tissenbaum et al. 2000).

Animal- and plant-parasitic nematodes use a variety of host-related and environmental cues for host finding and resumption of development (the latter is referred to as recovery). Important cues may include host-related volatiles, carbon dioxide, a change in $\mathrm{pH}$ or temperature and exposure to the hosts' digestive enzymes or to plant root diffusates (Lewis, Gaugler \& Harrison, 1993; Perry \& Aumann, 1998; Ashton, Li \& Schat, 1999). Host finding in $H$. bacteriophora is stimulated by hostrelated volatiles (Grewal et al. 1994) and by carbon dioxide (O'Halloran and Burnell, unpublished observations) whilst heterorhabditid DJ recovery in vitro is stimulated by carbon dioxide (Jessen et al. 2000) and a food signal secreted by the nematode's symbiotic bacterium (Strauch \& Ehlers, 1998).

Tracking the process of recovery in $H$. bacteriophora DJs is important from a commercial viewpoint. Whilst recovery is as high as $95 \%$ in an insect host, in liquid culture it varies enormously as the efficacy of the food signal in liquid is much lower (Strauch \& Ehlers, 1998) and there are no hostspecific cues. Therefore, in order to increase yields and decrease costs in liquid culture, improved methods for inducing recovery are necessary. These improvements may result from optimizing environmental conditions or developing new strains of nematode with improved recovery in liquid culture. However, in order to achieve such improvements, rapid and effective methods for detecting recovery are required. Here we describe a series of methods for improved detection of recovery in $H$. bacteriophora. We also describe some of the physiological changes that occur immediately after the onset of recovery in these nematodes as revealed using fluorescent nucleic acid binding dyes.

\section{MATERIALS AND METHODS}

\section{Biological material}

Heterorhabditis bacteriophora (strain HP88) was isolated in Utah, USA (Poinar \& Georgis, 1990) and maintained in vivo at $25^{\circ} \mathrm{C}$ in last instar Galleria mellonella larvae (The Mealworm Company, Sheffield, UK). Petri dishes $(9 \mathrm{~cm})$ were lined with Whatman no. 1 filter paper and $1 \mathrm{ml}$ of water containing approximately $500 \mathrm{DJ}$ sas added. Ten $G$. mellonella larvae were then placed in each Petri dish and the dishes were incubated at $25^{\circ} \mathrm{C}$ for $7-10$ days to allow the DJs to infect the insects. Infected insect larvae were placed on White traps (White, 1927), constructed by placing an inverted lid of a $5.5 \mathrm{~cm}$ Petri dish in the centre of a $9 \mathrm{~cm}$ diameter $\times 4 \mathrm{~cm}$ high plastic dish (Roundstone Catering Ltd, Reading, UK). A piece of $9 \mathrm{~cm}$ filter paper (Whatman no. 1) was positioned on the lid of the $5.5 \mathrm{~cm}$ Petri dish. Distilled water was added to the larger dish until the edges of the filter paper became immersed in the water. The G. mellonella cadavers were placed on the platform formed by the lid of the $5.5 \mathrm{~cm}$ Petri dish. Five cadavers were placed in each White trap and incubated at $25^{\circ} \mathrm{C}$.

White traps were monitored by microscopical examination each day until DJs were observed in the water. Once DJs began to emerge from the insect cadavers, they were collected daily from the trap by pouring the trap water into $50 \mathrm{ml}$ conical tubes. The water trap was rinsed 3 times to ensure all DJs were harvested (O'Leary et al. 1998). The DJs were allowed to settle in conical tubes and washed 3 times with distilled water. These freshly harvested DJs were then stored in distilled water (approximately $5000 \mathrm{DJs} / \mathrm{ml}$ ) at $20^{\circ} \mathrm{C}$ in $9 \mathrm{~cm}$ diameter $\times 2 \mathrm{~cm}$ high plastic dishes (Roundstone Catering Ltd, Reading, UK) until required. It required approximately 1 week for all the DJs to emerge from a $G$. mellonella cadaver and DJs were pooled 1-3 weeks after emergence. It has previously been shown that DJs of different ages react to stimuli at different rates (O'Leary et al. 1998). Therefore DJs of the same age (3 weeks old) were used in all experiments, unless otherwise stated.

\section{Induction of D尹 recovery}

In our first experiments we determined the most efficient way of inducing DJ recovery under experimental conditions. The efficiency of using lipid agar plates streaked with the bacterial symbiont, Photorhabdus luminescens and using G. mellonella cadavers were compared. Bacterial plates were prepared by streaking lipid agar plates (Dunphy \& Webster, 1989) with $P$. luminescens bacteria, prepared using standard protocols (Akhurst, 1980, 1986), and incubating at $30^{\circ} \mathrm{C}$ for $48 \mathrm{~h}$. Approximately $100 \mathrm{DJs}$ were pipetted onto each plate and incubated for different time-periods at $25^{\circ} \mathrm{C}$. $G$. mellonella cadavers were prepared by haemocoelic injection of $P$. luminescens cells (Dix et al. 1992). The injected insect larvae were incubated at $25^{\circ} \mathrm{C}$ and after 3 days they were checked for death and 
bioluminescence. Approximately $100 \mathrm{DJs}$ were injected into the cadavers using a microcapillary. Alternatively, the cadavers were surface sterilized using absolute alcohol and were placed on lipid agar plates and opened by a mid-ventral incision. Then approximately $100 \mathrm{DJ}$ s were pipetted onto the open cadaver. The cadavers were then incubated for various time-periods at $25^{\circ} \mathrm{C}$. The nematodes were washed off the lipid agar plates and the open cadaver plates using $\mathrm{M} 9$ buffer $(85.5 \mathrm{mM} \mathrm{NaCl}, 42 \mathrm{mM}$ $\mathrm{Na}_{2} \mathrm{HPO}_{4}, 22 \mathrm{~mm} \mathrm{KH}_{2} \mathrm{PO}_{4}, 1 \mathrm{~mm} \mathrm{MgSO}_{4} .7 \mathrm{H}_{2} \mathrm{O}$ ) and scored for recovery by morphological changes (see below). The closed cadavers were opened by a mid-ventral incision and incubated in M9 buffer for $20 \mathrm{~min}$ to extract the recovering nematodes from the cadavers. The effect of nematode age on efficiency of recovery was also examined. The time taken for DJs of various ages (1-5 weeks old) to recover on $G$. mellonella cadavers was examined by pipetting $100 \mathrm{DJ}$ s onto cadavers as described above. The proportion of DJs which started recovery, as assessed by morphological changes, was examined at various time-points from 9-36 h.

\section{Detection of recovery}

The efficiency and convenience of several different methods of detecting recovery were compared. The methods used are described below.

\section{Morphological changes}

When DJs begin to recover the head region swells and the 2nd-stage juvenile (J2) cuticle is shed. This swelling and loss of cuticle indicates that recovery has begun and that the nematode will soon begin to feed. To observe these changes, the recovering nematodes were pipetted onto clean microscope slides and observed under the $40 \times$ objective of a Zeiss Axiovert binocular microscope.

\section{Microsphere assay}

The uptake of fluorescent latex microspheres (Molecular Probes: $0.02 \mu \mathrm{m}$, cat. no. F-8787; $0.1 \mu \mathrm{m}$, cat. no. F-8803 or $1.0 \mu \mathrm{m}$, cat. no. F-8823) into the digestive tract was used as a method of monitoring recovery. Recovery was initiated in DJs using open $G$. mellonella cadavers as described above. After various time-periods, the recovering DJs were recovered from the cadavers, washed in M9 buffer and adjusted to a final concentration of $100 \mathrm{DJs} / \mathrm{ml}$. Ten $\mathrm{ml}$ of this nematode suspension were then transferred to another $5.5 \mathrm{~cm}$ Petri dish and $10 \mu \mathrm{l}$ of microsphere stock solution added. The nematode/ microsphere solution was then gently mixed and incubated at $25^{\circ} \mathrm{C}$ in the dark for $30 \mathrm{~min}$. The nematodes were washed 3 times with sterile M9 buffer and observed using a Zeiss Axiovert fluorescence microscope fitted with a standard FITC filter (FT 510) using an excitation spectrum of $450-490 \mathrm{~nm}$ and an emission wavelength of $510 \mathrm{~nm}$. The efficiency of ingestion of spheres of different sizes $(0.02 \mu \mathrm{m}, 0.1 \mu \mathrm{m}$ and $1 \mu \mathrm{m})$ was compared. Uptake of fluorescent microspheres was examined at various time points from 5 to $96 \mathrm{~h}$ after initiation of recovery.

\section{Analysis of changes in RNA levels using SYTO dyes}

A series of experiments using nematodes allowed to recover for periods of $2-36 \mathrm{~h}$ was performed in order to track physiological changes that occur during this phase of the nematode's life-cycle. Recovering nematodes were extracted from plates and washed 3 times with $20 \mathrm{ml}$ of phosphate-buffered saline (PBS-137 mM NaCl, $1.4 \mathrm{mM} \quad \mathrm{KH}_{2} \mathrm{PO}_{4}, \quad 2.6 \mathrm{~mm}$ $\mathrm{KCl}, 8.1 \mathrm{mM} \mathrm{Na} \mathrm{HPO}_{4}, \mathrm{pH} 7 \cdot 4$ ). The nematodes were then centrifuged and incubated in dimethyl sulfoxide as described by Blair et al. (1999). Then the nematodes were washed 3 times with PBS and incubated in SYTO-12 (Molecular Probes, cat no. $\mathrm{S}-7574$ ) at a final concentration of $50 \mathrm{mg} / \mathrm{ml}$ for $2 \mathrm{~h}$ at $37^{\circ} \mathrm{C}$ in the dark on a rotary shaker. The stained nematodes were then washed 3 times with PBS, mounted on slides and viewed with an MRC 1000 confocal laser scanning microscope (CSLM) to image the fluorescent dye. Blue laser excitation light (488 nm wavelength) was generated from a $25 \mathrm{~mW}$ krypton/argon laser and fluorescence at $525 \mathrm{~nm}$ (close to the emission maximum for SYTO-12 bound to RNA) was examined. Images were stored using the CSLM software and processed using Photoshop software (Adobe, Mountain View, CA). Controls of DJs not subjected to the recovery induction process were used throughout.

\section{Statistical methods}

The data are presented as the mean \pm s.E.M. Anderson-Darling normality tests indicated that the data means conformed to the normal probability distribution $(P<0.05)$. Two-way analysis of variance (ANOVA) and one-way ANOVA were carried out. Statistical significance was tested using Tukey's pair-wise comparison method at the $P<0.05$ significance level.

\section{RESULTS}

\section{Induction of recovery}

Dauer larvae began the process of recovery on all media tested. Recovery on open $G$. mellonella 


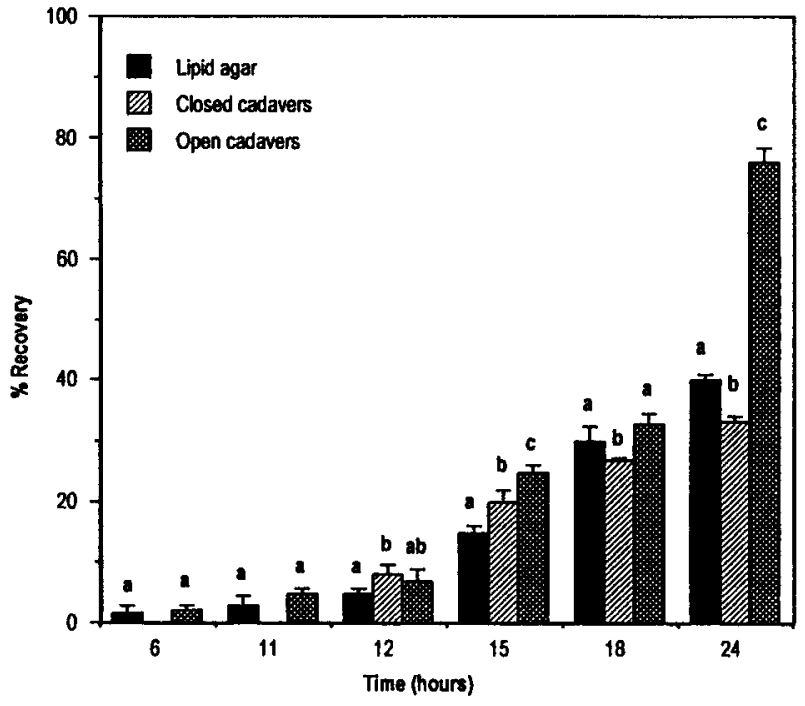

Fig. 1. Recovery of Heterorhabditis bacteriophora on different media at $25^{\circ} \mathrm{C}$. The percentage recovery of $H$. bacteriophora $\mathrm{DJ}$ s on lipid agar plates streaked with the bacterial symbiont Photorhabdus luminescens, on intact cadavers of Galleria mellonella and opened cadavers of G. mellonella is compared at various time-points after the DJs were placed on the recovery media. Recovery was monitored using morphological markers. Each bar represents the mean \pm s.e. of 3 replicates. For each timepoint means followed by the same letter are not significantly different; $P<0.05$.

cadavers was faster than that when DJs were injected into closed $G$. mellonella cadavers or placed on lipid agar plates streaked with $P$. luminescens (Fig. 1). Therefore, incubation of DJs on prepared opened $G$. mellonella cadavers was the method of choice for inducing recovery in subsequent experiments. The experiments examining the effect of nematode age on recovery showed that 3 -week-old nematodes had the highest levels of recovery (Fig. 2).

\section{Detection of recovery}

All 3 methods tested could be used to detect recovery. However, the methods varied in their efficiency and in their convenience. Each is considered in detail below.

(1) Morphological changes. Several morphological changes could be used to detect recovery in DJs. These included the loss of the sheath (i.e. the J2 cuticle which is retained by the 3 rd-stage DJs) and development to the 4th-stage juvenile (J4) (Fig. 3). At earlier stages, it was possible to detect a change in the morphology of the anterior of recovering DJs, with the recovering nematodes being slightly enlarged and showing a more obvious pharynx (Fig. 4). Detecting such changes was a subjective process and required an experienced observer for reliable detection.

(2) Microsphere assay. Fluorescent microspheres of $0.02 \mu \mathrm{m}$ and $0.1 \mu \mathrm{m}$ were ingested into the intestine by recovering DJs and provided a convenient marker for the onset of recovery (Fig. 5). Larger microspheres $(1 \mu \mathrm{m})$ were not taken up efficiently by

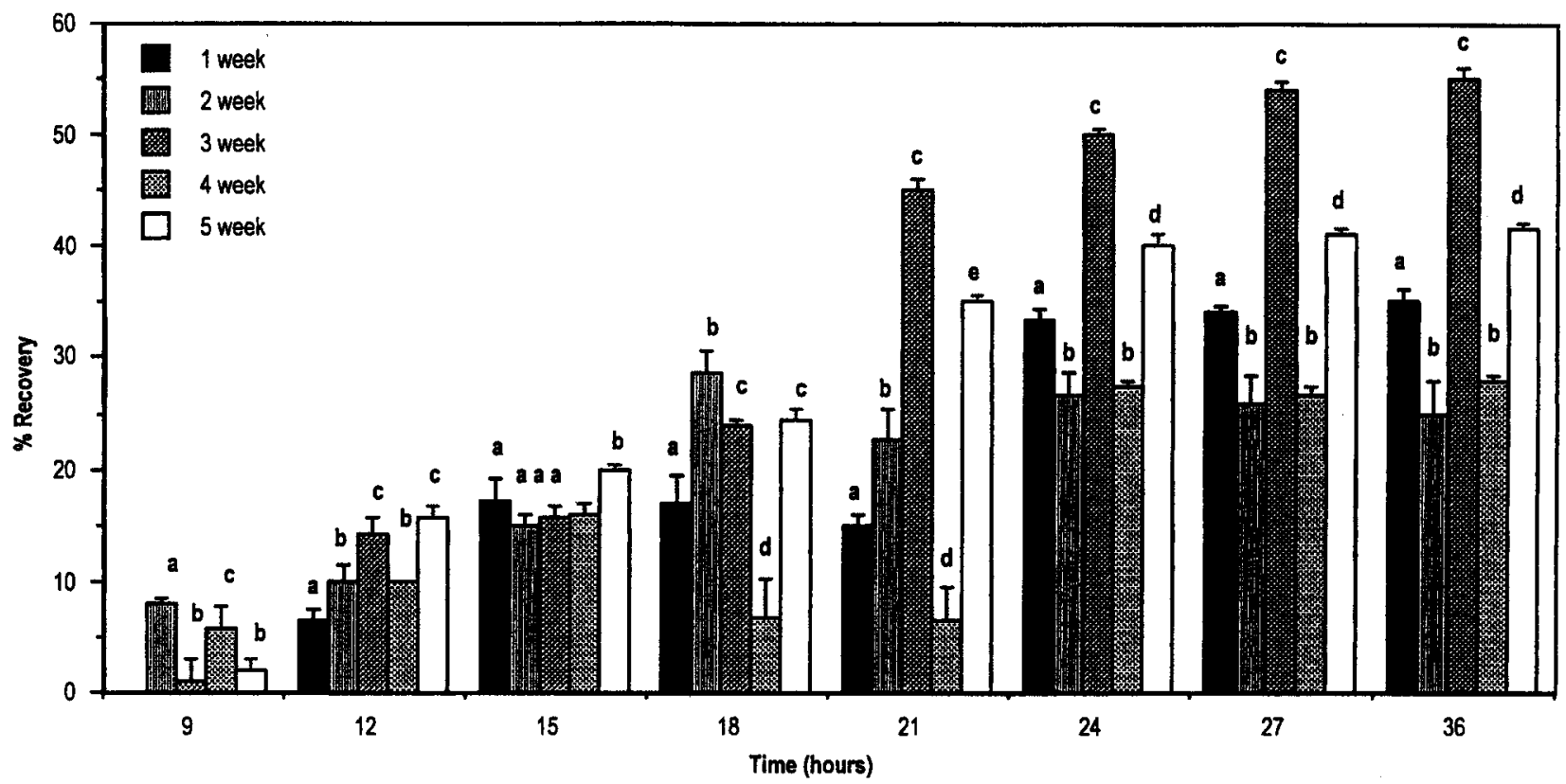

Fig. 2. The effect of DJ age on recovery in Heterorhabditis bacteriophora. The rate of recovery of $H$. bacteriophora DJs between 1 and 5 weeks old was monitored at various time-points after the DJs were placed on the recovery media. Recovery was induced on opened cadavers of Galleria mellonella at $25^{\circ} \mathrm{C}$. Each bar represents the mean \pm s.E. of 5 replicates. For each time-point means followed by the same letter are not significantly different; $P<0 \cdot 05$. 

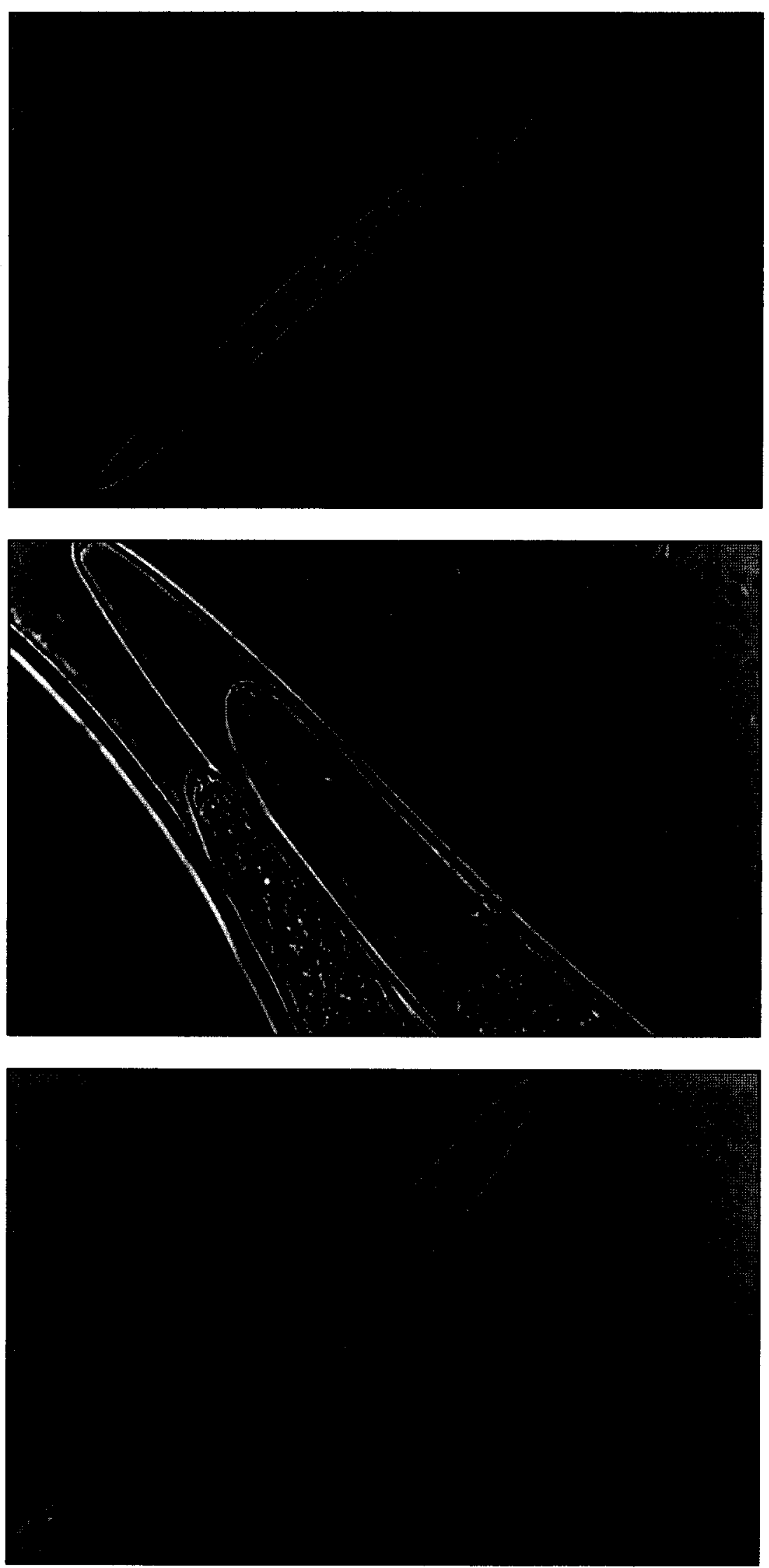

Fig. 3. Morphological changes during Heterorhabditis bacteriophora DJ recovery. (A) DJ enclosed in the sheath (J2 cuticle) showing a thin body with closed digestive system; (B) recovering DJs showing loss of the sheath; (C) the J4 stage has a wider body diameter than unrecovered DJs. 

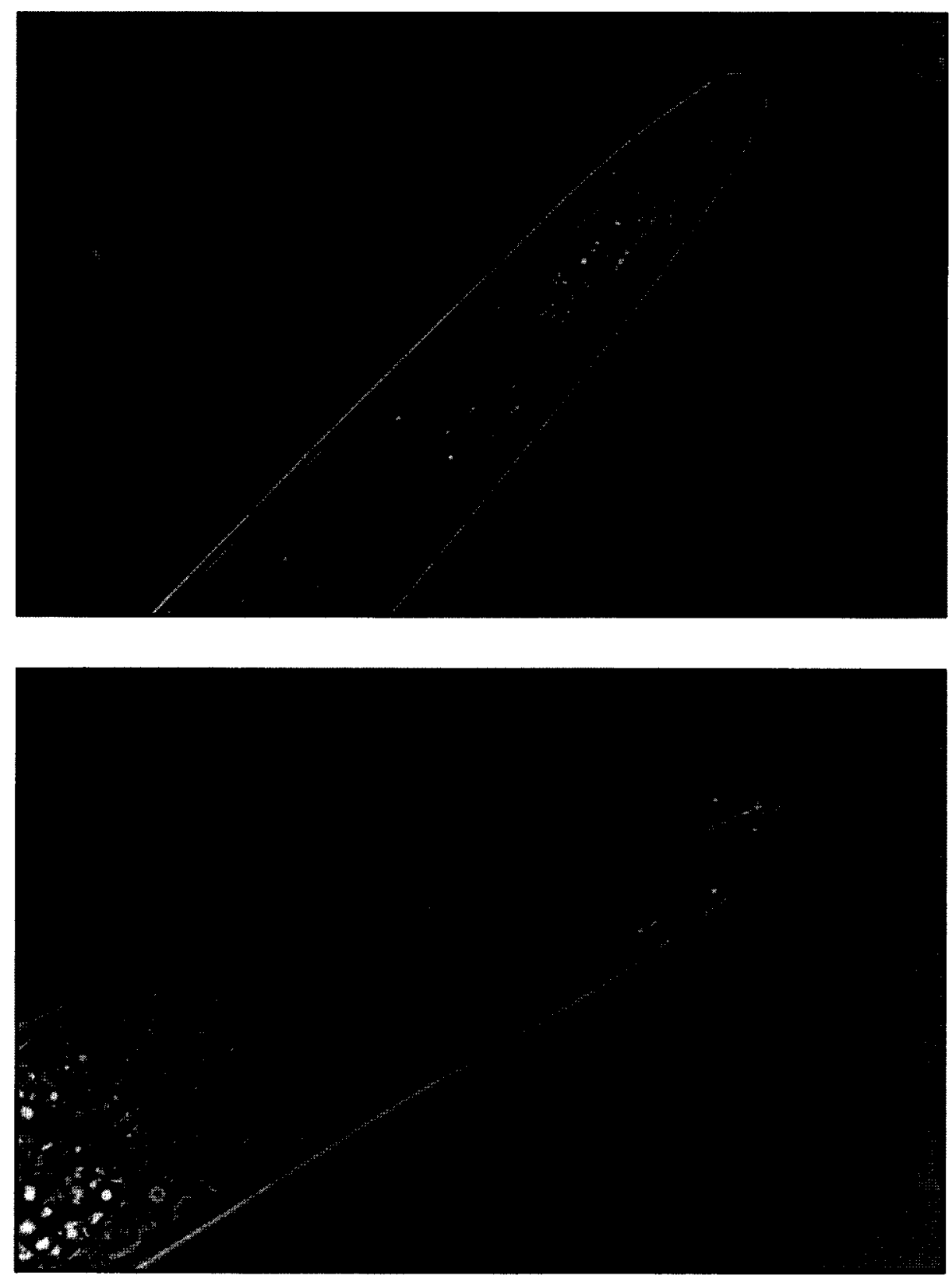

Fig. 4. Changes in morphology of the head region which occur soon after the onset of recovery. (A) Pointed head region of $\mathrm{DJ}$; (B) a recovered $\mathrm{DJ}$ showing a rounded and more truncate head region.

recovering DJs of any age, although these microspheres were ingested by later developmental stages such as $\mathrm{J} 4$ and adults (Fig. 6). During the earliest stages of recovery the $0 \cdot 1 \mu \mathrm{m}$ microspheres were ingested with the greatest efficiency but, by $15 \mathrm{~h}$ after the initiation of recovery, there was no difference between the uptake of these and the $0.02 \mu \mathrm{m}$ microspheres (Fig. 6).

Using microspheres it was possible to detect recovery more efficiently in DJs soon after initiation as compared to using morphological markers alone (Fig. 7). Using the microspheres it was possible to detect recovery in $20 \%$ of DJs just $5 \mathrm{~h}$ after initiation whereas no recovering $\mathrm{DJs}$ were detected at this time-point using morphological markers. Statistical analysis of the numbers of recovering DJs detected by microsphere uptake compared with the numbers detected using morphological markers showed that significantly more recovering DJs were detected by the microsphere method (Fig. 7). Detecting recovering DJs using microspheres was considerably more straightforward than detecting recovery using morphological markers. It was also possible to examine greater numbers of DJs in a shorter time using microspheres than when attempting to discern morphological differences.

(3) Analysis of changes in RNA levels using SYTO dyes. SYTO-12 showed specific and reproducible staining of recovering DJs as soon as $3 \mathrm{~h}$ after initiation of recovery and was therefore a useful 

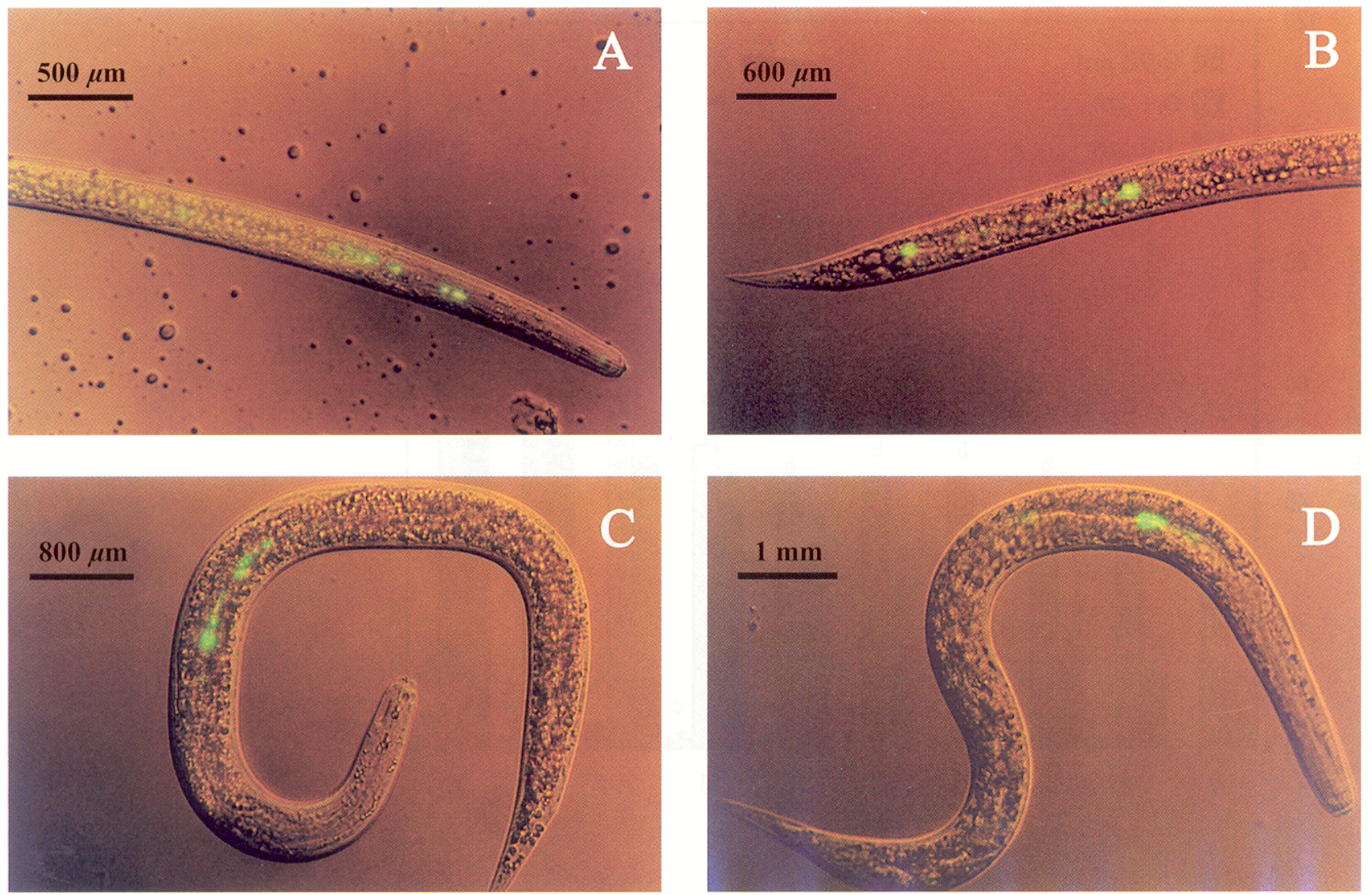

Fig. 5. Uptake of fluorescent latex microspheres $(0 \cdot 1 \mu \mathrm{m}$ diameter $)$ by recovering Heterorhabditis bacteriophora. The microspheres were ingested by recovered nematodes which had recommenced feeding. (A) The presence of spheres in the anterior intestinal region of a nematode after $3 \mathrm{~h}$ in recovery media (prepared Galleria mellonella cadavers); (B) spheres in the posterior intestinal region of a recovered DJ following a $30 \mathrm{~min}$ exposure to microspheres $3 \mathrm{~h}$ after the onset of recovery; (C) after $15 \mathrm{~h}$ on recovery media the nematodes (J4) readily ingested the spheres, these can be seen throughout the intestine; (D) spheres of varying size present in the intestine of an adult hermaphrodite.

marker of the recovery process (Fig. 8). SYTO-12 staining in the pharyngeal gland cells was apparent $3 \mathrm{~h}$ after being placed in recovery media, suggesting high levels of transcriptional activity in these cells (Fig. 8B and C). This binding was intense, reproducible and easily distinguishable from autofluorescence. Intense staining was also detected in the cells of the ventral and dorsal ganglia located between the nerve ring and the pharyngeal gland cells. A similar staining pattern was also observed $6 \mathrm{~h}$ after initiation of recovery (Fig. 8D and E). After $6 \mathrm{~h}$, SYTO-12 staining of the genital primordia was also observed (Fig. 8E). This staining was also observed after $12 \mathrm{~h}$ (Fig. 8F and $\mathrm{G}$ ) at which point more cells were visible in this tissue. Indeed it was possible to observe development of the genital primordia using SYTO-12 by staining nematodes at different time-points after initiation of recovery (not shown). Controls, using DJs incubated in the SYTO-12 dye showed no staining in either the gland cells or genital primordia, although slight autofluorescence was seen in the amphidial region. Some partitioning of the (hydrophobic) dye into lipid droplets and membranes was observed in control specimens (Fig. 8A).

\section{DISCUSSION}

We found that the most efficient method for inducing recovery was to introduce DJs to cadavers of $G$. mellonella which had previously been opened by a mid-ventral incision. We also found that using 3week-old DJs gave the highest recovery results. The recovery rates which we obtained in open cadavers were similar to those recorded by Strauch \& Ehlers (1998) from infecting live hosts. These authors found that, although the symbiont bacteria do secrete a food signal which is necessary for recovery, recovery is much lower and more variable in liquid culture than in G. mellonella. After 4 days in liquid culture medium mean recovery rates ranged from 23 to $48 \%$, whereas mean recovery rates in G. mellonella 24 h p.i. ranged from 83 to $98 \%$ (Strauch \& Ehlers, 1998). Insect parasitic nematodes orient along carbon dioxide gradients during host finding (Gaugler et al. 1994) and $\mathrm{CO}_{2}$ also acts synergistically with the food signal to enhance heterorhabditid DJ recovery in vitro (Jessen et al. 2000).

The development of strains of $H$. bacteriophora with improved recovery in liquid culture conditions is a commercially important target, but in order to 


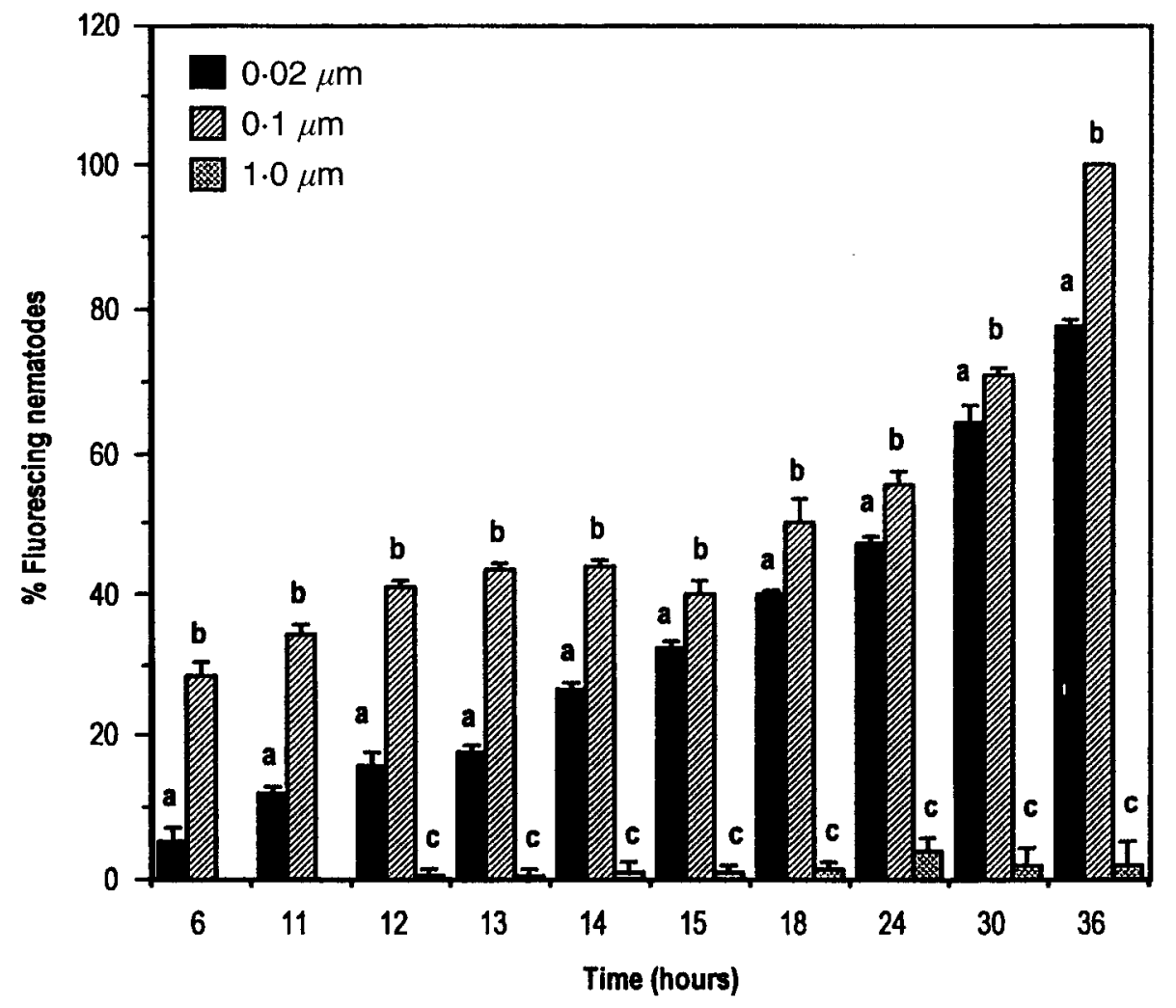

Fig. 6. A comparison of the uptake of microspheres of 3 different sizes by recovering DJs of Heterorhabditis bacteriophora. Recovery was initiated on opened cadavers of Galleria mellonella. Each bar represents the mean \pm s.E. of 5 replicates. For each time-frame, means followed by the same letter are not significantly different $; P<0 \cdot 05$.

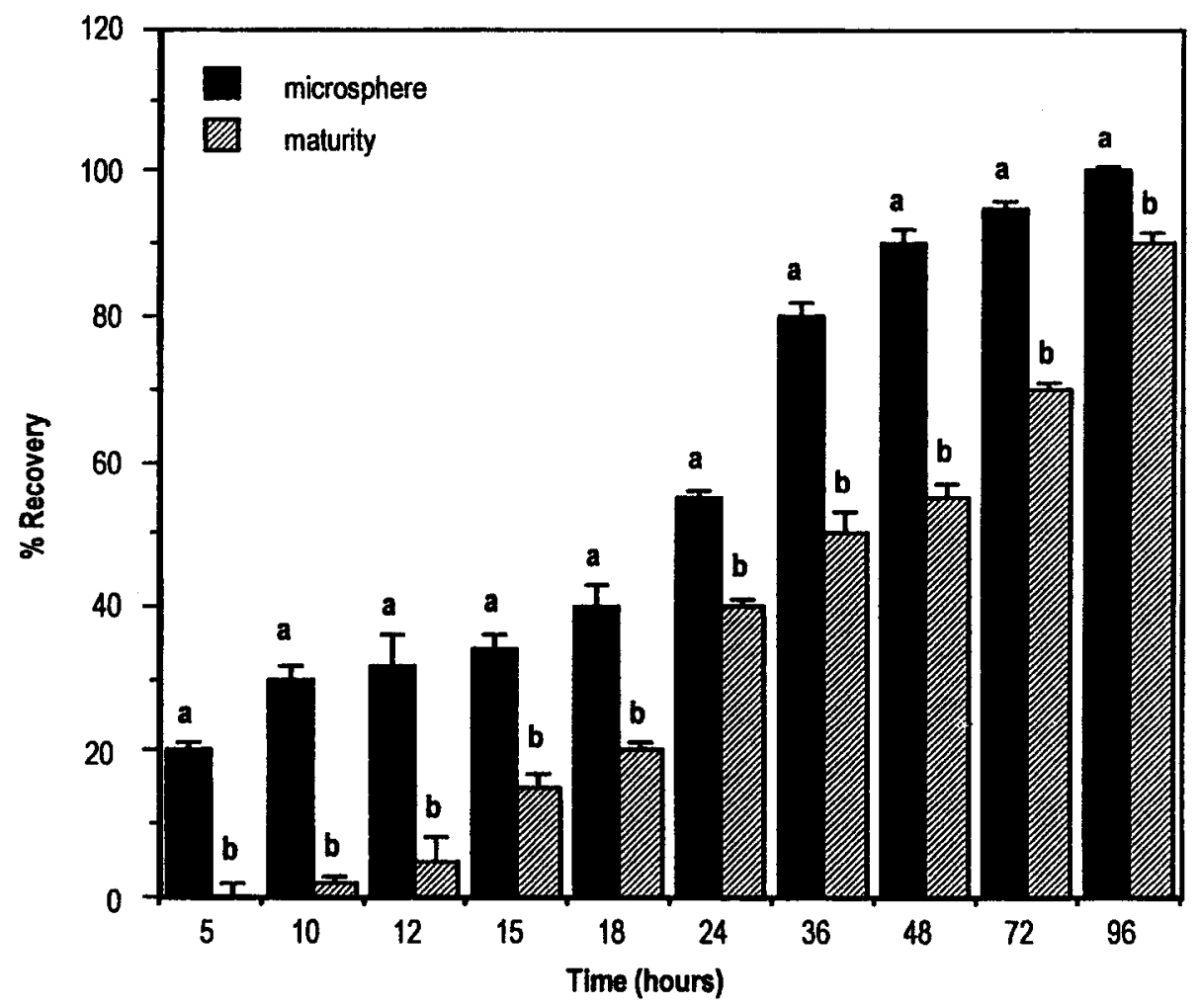

Fig. 7. A comparison of the efficiency of detection of recovery using morphological markers and $0 \cdot 1 \mu \mathrm{m}$ fluorescent microspheres. Recovery was initiated on opened cadavers of Galleria mellonella. Each bar represents the mean \pm s.E. of 5 replicates. For each time-frame, means followed by the same letter are not significantly different $; P<0 \cdot 05$. 

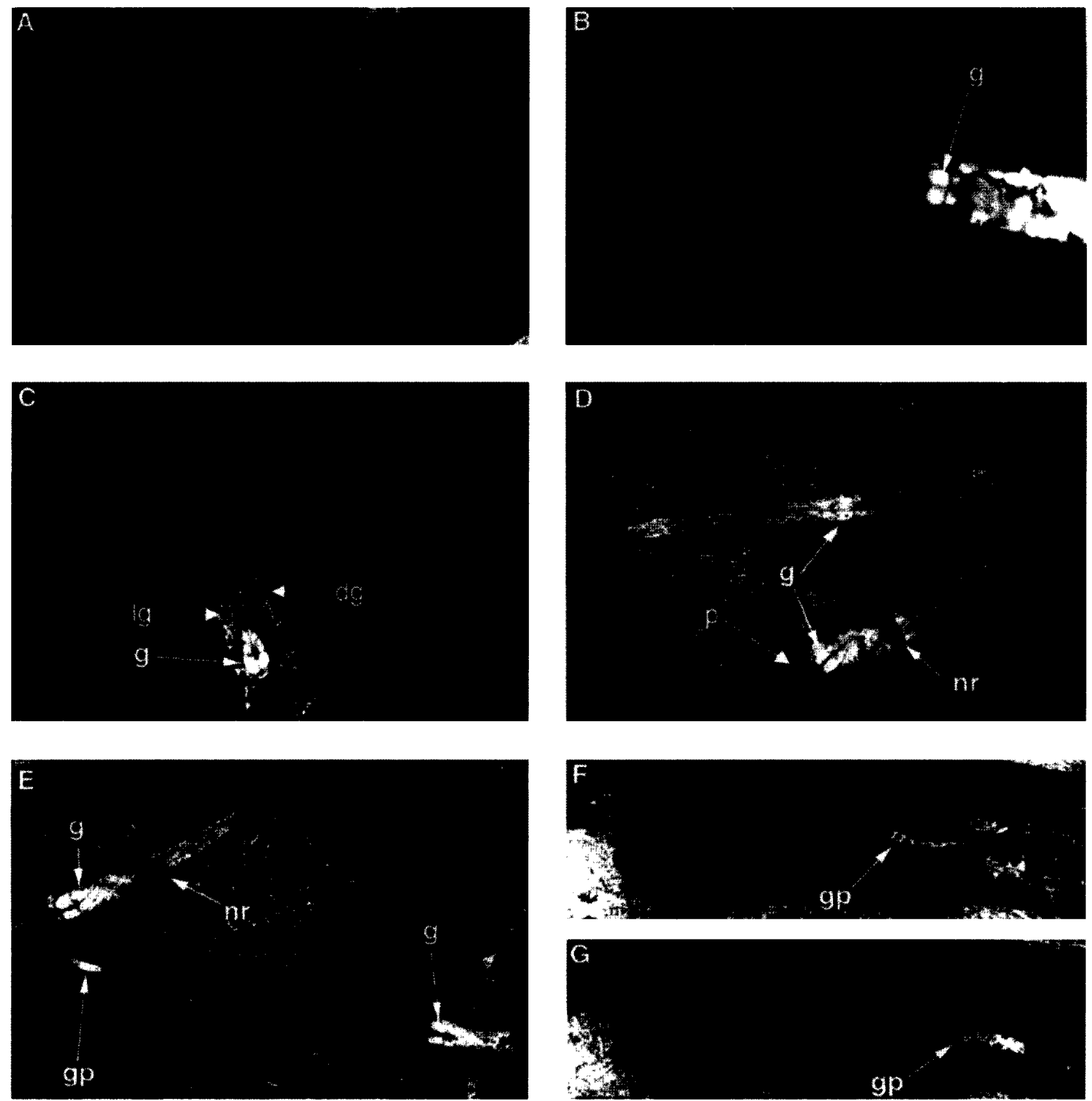

Fig. 8. A time-course experiment using the nucleic acid-binding dye SYTO-12 staining in recovered DJs of

Heterorhabditis bacteriophora. (A) Non-recovered control dauers show no obvious staining of any cell bodies, though slight autofluorescence is observed, (B) intense staining of the pharyngeal gland cells ( $\mathrm{g}$ ) after $3 \mathrm{~h}$ recovery, (C) staining of the dorsal ganglia $(\mathrm{dg})$ and lateral ganglia $(\mathrm{lg})$, as well as staining of cell bodies within the gland cells $(\mathrm{g})$ with less intensity, after $6 \mathrm{~h}$ DJ recovery. (D) By $6 \mathrm{~h}$ after recovery the pharyngeal bulb (p) is observed below the gland cells, as are nuclei of the cell bodies within the pharyngeal glands $(\mathrm{g})$. The nerve ring (nr) is visible as a dark structure into which dye does not partition. (E) Within $6 \mathrm{~h}$ of being introduced to a food source, staining of the genital primordia $(\mathrm{gp}$ ) occurs as the intensity in $(\mathrm{g})$ decreases. ( $\mathrm{F}$ and $\mathrm{G}$ ) Higher magnification images showing staining of the nucleoli of the genital primordia (gp) $12 \mathrm{~h}$ after the onset of recovery. The two images show different optical sections of the same nematode and illustrate the cell divisions that have taken place in this structure.

achieve this aim it is important to have methods available that allow rapid and straightforward detection of recovery from the dauer stage. Recovering DJs are currently identified by subtle changes in morphology (Strauch \& Ehlers, 1998) but detecting these changes, particularly in nematodes soon after initiation of recovery, is a time-consuming process and one that requires a skilled and experienced observer. We have investigated 2 methods that provide an alternative to this procedure.

The use of fluorescent latex microspheres was found to be an efficient method of detecting recovery in $H$. bacteriophora, although the size of microspheres used was found to be an important factor. DJs which had begun to recover, and hence had started feeding, ingested the microspheres and these 
were readily visible in their intestines when viewed under a fluorescence microscope. As well as allowing earlier detection of recovery, this method allowed rapid screening of large numbers of nematodes on microscope slides and thus provided an efficient method of scoring recovery in large numbers of nematodes.

A fluorescent dye, SYTO-12, which binds to RNA was also found to be a useful indicator for the onset of recovery. This dye stained the pharyngeal gland cells of nematodes as soon as $3 \mathrm{~h}$ after the DJs had been placed on recovery media and this provided the earliest marker for recovery in $H$. bacteriophora. From a practical point of view this technique was not as simple to use as the microspheres and, therefore, despite the capacity of SYTO-12 to detect recovery slightly sooner than microspheres, it seems likely that microspheres will be more useful for routine screening of nematode strains for improved recovery traits.

Staining of a cell with SYTO-12 implies that the cell contains markedly higher levels of RNA than other cells and that it is in the process of, or preparing to, synthesize unusually large quantities of protein (Haugland, 1996). Therefore, analysis of the cell types stained with SYTO-12 may reveal information about physiological changes occurring in an organism. Two cell types were stained in recovering $H$. bacteriophora, the pharyngeal gland cells and the genital primordia. The cells making up genital primordia undergo a series of rapid divisions as they mature to form the reproductive tissues of the adult nematode. Since this process, and the synthesis of the reproductive materials that follows, is one that requires a large amount of protein it is perhaps not surprising that the cells making up the genital primordia contain a lot of RNA and stain with SYTO-12. Indeed, similar findings have been reported in studies performed on other nematodes using nucleic acid binding dyes. Studies on the plant-parasitic nematode Globodera rostochiensis (Blair et al. 1999) and on the animal parasite Trichinella spiralis (Janssen, Tetley \& Kennedy, 1998) showed that the genital primordia of these nematodes stained with nucleic acid binding dyes. Both of these studies were performed with the developmental equivalents of the $H$. bacteriophora DJ (the hatching J2 of $G$. rostochiensis and the infective 3 rd-stage juvenile of $T$. spiralis) and it seems likely that developmental activation of the genital primordia may be a process that occurs rapidly in all nematodes upon exit from a dauer-like stage.

The earliest physiological event that it was possible to detect in any of our experiments was an increase in transcriptional activity in the pharyngeal gland cells of recovering DJs. This change was initiated within a few hours of exposure to a food source and implies that the gland cells produce large quantities of proteins which are important in the earliest phases of the infection and/or feeding process. The data obtained here for $H$. bacteriophora parallel those found for $G$. rostochiensis. One of the earliest events that occurred during hatching (which equates to recovery from the dauer stage) in $G$. rostochiensis was an increase in the transcriptional activity of the dorsal and subventral pharyngeal gland cells (Blair et al. 1999). It is known that in $G$. rostochiensis (and other plant parasites) these gland cells produce a variety of proteins important in invasion of the host, such as cellulases and pectate lyases (Smant et al. 1998; Popeijus et al. 2000), as well as other proteins which may be important in the feeding process (Qin et al. 2000). Although nothing is yet known about the proteins produced by the gland cells of $H$. bacteriophora during recovery, they may also have roles in the pathogenesis in this nematode, possibly in infection of the insect host, or in the process of killing or digesting the host after invasion has occurred. Further characterization of such proteins may yield scientifically and commercially important information about the infection of insects by nematodes.

This work was funded by the European Union project number FAIR3-CT97-3116 (A.M.B.), by a European Union COST 819 Short Term Training Mission (K.M.D.) and by Scottish Executive Rural Affairs Division project number SCR/514/98 (J.T.J.). The authors thank Dr A. Roberts for assistance with confocal microscopy.

\section{REFERENCES}

AKHURST, R. J. (1980). Morphological and functional dimorphism in Xenorhabdus spp., bacteria symbiotically associated with the insect pathogenic nematodes Neoaplectana and Heterorhabditis. Fournal of General Microbiology 121, 303-309.

AKHURST, R. J. (1986). Xenorhabdus, a genus of bacteria symbiotically associated with the insect pathogenic nematodes. International Fournal of Systematic Bacteriology 33, 38-45.

AKHURST, R. J. \& BEDDING, R. A. (1986). Natural occurrence of insect parasitic nematodes (Steinernematidae, Heterorhabditidae) in soil in Australia. Journal of the Australian Entomology Society 25, 241-244.

AShton, F. T., LI, J. \& SCHAT, G. A. (1999). Chemo- and thermosensory neurons: structure and function in animal parasitic nematodes. Veterinary Parasitology 84, 279-316.

BLAIR, L., PERry, R. N., OPARKA, K. \& JONES, J. T. (1999). Activation of transcription during the hatching process of the potato cyst nematode Globodera rostochiensis. Nematology 1, 103-111.

BLAXTER, M. L., DE LEY, P., GAREY, J. R., LIU, L. X., SCHELDEMAN, P., VIERSTRAETE, A., VANFLETEREN, J. R., MACKEY, L. Y., DORRIS, M., FRISSE, L. M., VIDA, J. T. \& 
THOMAs, w. K. (1998). A molecular evolutionary framework for the phylum Nematoda. Nature, London 392, 71-75.

BoEmaRe, N. E., AKHURST, R. J. \& MOURANT, R. G. (1993).

DNA relatedness between Xenorhabdus spp.

(Enterobacteriaceae), symbiotic bacteria of entomopathogenic nematodes, with a proposal to transfer Xenorhabdus luminescens to a new genus Photorhabdus gen. nov. International Fournal of Systematic Bacteriology 43, 249-255.

BURNELL, A. M. \& STOCK, P. (2000). Heterorhabditis, Steinernema and their bacterial symbionts - lethal pathogens of insects. Nematology 2, 31-42.

CASSADA, R. C. \& RUSSELL, R. L. (1975). The dauer larva, a post-embryonic developmental variant of the nematode Caenorhabditis elegans. Developmental Biology 46, 326-342.

DIX, I., BURNELl, A. M., GRIFFIN, c. T., JOYCE, S. A., NUGENT, M. J. \& Downes, M. J. (1992). The identification of biological species in the genus Heterorhabditis (Nematoda: Heterorhabditidae) by cross-breeding second generation amphimictic adults. Parasitology 104, 509-518.

DUNPHY, G. B. \& WEBSTER, J. M. (1989). The monoxenic culture of Neoaplectana carpocapsae DD136 and Heterorhabditis heliothidis. Revue de Nématologie 12, 113-123.

FORST, S., DOWDS, B., BOEMARE, N. \& STACKEBRANDT, E. (1997). Xenorhabdus and Photorhabdus spp.: Bugs that kill bugs. Annual Review of Microbiology 51, 47-72.

GAUGLeR, R., GLAZER, I., CAMPBELL, J. F. \& LIRAN, N. (1994). Laboratory and field-evaluation of an entomopathogenic nematode genetically selected for improved host-finding. Fournal of Invertebrate Pathology 63, 68-73.

GOLDEN, J. W. \& RIDDLE, D. L. (1984). A pheromone induced developmental switch in Caenorhabditis elegans: temperature sensitive mutants reveal a wild type temperature dependent process. Proceedings of the National Academy of Sciences, USA 81, 819-823.

GRANT, W. N. \& VINEY, M. E. (2001). Post-genomic nematode parasitology. International fournal for Parasitology 31, 879-888.

GREWAL, P. S., LEWIS, E. E., GAUGLER, R. \& CAMPBELL, J. F. (1994). Host finding behavior as a predictor of foraging strategy in entomopathogenic nematodes. Parasitology 108, 207-215.

HAUGland, R. P. (1996). Handbook of Fluorescent Probes and Research Chemicals. Molecular Probes Inc., Eugene, OR.

JANSSEN, C. S., TETLEY, L. \& KENNEDY, M. W. (1998). Developmental activation of infective Trichinella spiralis larvae. Parasitology 117, 363-371.

JESSEN, P., STRaUCh, o., wyss, U., LUTTMANN, R. \& EHLERS, R.-U. (2000). Carbon dioxide triggers recovery from dauer juvenile stage in entomopathogenic nematodes (Heterorhabditis spp.). Nematology 2, 319-324.
KLEIN, M. G. (1990). Efficacy against soil-inhabiting insect pests. In Entomopathogenic Nematodes in Biological Control (ed. Gaugler, R. \& Kaya, H. K.), pp. 195-210. CRC Press, Boca Raton, Florida.

LEWIS, E. E., GAUGLER, R. \& HARRISON, R. (1993). Response of cruiser and ambusher entomopathogenic nematodes to host volatile cues. Canadian Fournal of Zoology 71, 765-769.

o'LEARY, S. A., STACK, C. M., CHUBB, M. A. \& BURNELL, A. M. (1998). The effect of day of emergence from the insect cadaver on the behavior and environmental tolerances of $\mathrm{IJs}$ of the entomopathogenic nematode Heterorhabditis megidis (strain UK211). Fournal of Parasitology 84, 665-672.

PERRY, R. N. \& AUMANN, J. (1998). Behaviour and sensory responses. In The Physiology and Biochemistry of FreeLiving and Plant-Parasitic Nematodes (ed. Perry, R. N. \& Wright, D. J.), pp. 75-102. CABI Publishing Wallingford, Oxon., UK.

POINAR, G. O. Jr. \& GEORGIS, R. (1990). Description and field application of the HP88 strain of Heterorhabditis bacteriophora. Revue de Nématologie 13, 387-393.

popeijus, H., OVERMARS, H., JONES, J. T., BLOK, V. C., GOVERSE, A., HELDER, J., SCHOTS, A., BAKKER, J. \& SMANT, G. (2000). Degradation of plant cell walls by a nematode. Nature, London 406, 36-37.

QIN, L., OVERMARS, B., HELDER, J., POPEIJUS, H., VAN DER VOORT, J. R., GROENINK, W., VAN KOERT, P., SCHOTS, A., BAKKER, J. \& SMANT, G. (2000). An efficient cDNAAFLP-based strategy for the identification of putative pathogenicity factors from the potato cyst nematode Globodera rostochiensis. Molecular Plant-Microbe Interactions 13, 830-836.

RIDDLE, D. L. \& ALBERT, P. S. (1997). Regulation of dauer larva development. In $C$. elegans $I I$ (ed. Riddle, D. L., Blumenthal, T., Meyer, B. J. \& Priess, J. R.), pp. 739-768. Cold Spring Harbor Laboratory Press, Cold Spring Harbor, New York.

SMANT, G., STOKKERMANS, J. P. W. G., YAN, Y., DE BOER, J. M., BAUM, T. J., WANG, X., HUSSEY, R. S., GOMMERS, F. J., HENRISSAT, B., DAVIS, E. L., HELdER, J., SCHOTS, A. \& BAKKER, J. (1998). Endogenous cellulase in animals: isolation of $\beta$-1, 4-endoglucanase genes from two species of plant-parasitic cyst nematodes. Proceedings of the National Academy of Sciences, USA 95, 4906-4911.

STRAUCH, O. \& EHLERS, R.-U. (1998). Food signal production of Photorhabdus luminescens inducing the recovery of entomopathogenic nematodes Heterorhabditis spp. in liquid culture. Applied Microbiology and Biotechnology 50, 369-374.

Tissenbaum, H. A., haWdon, J., PERREgauX, M., hotez, P., GUARENTE, L. \& RUVKUN, G. (2000). A common muscarinic pathway for diapause recovery in the distantly related nematode species Caenorhabditis elegans and Ancylostoma caninum. Proceedings of The National Academy of Sciences, USA 97, 460-465.

WHITE, G. F. (1927). A method for obtaining infective nematode larvae from cultures. Science 66, 302-303. 